\title{
Research on Water Scarcity in North China
}

\author{
Yuhe Fu \\ School of North China Electric Power University (Baoding), Baoding 071000, China; \\ xxfs3r@163.com
}

Keywords: water consumption, water supply, water scarcity

\begin{abstract}
Water issues have risen in prominence in recent years. Based on the issue of water shortage in North China Plain, some of the basic models are outlined in this paper to analyze and forecast the supply and demand of water resources. Comparing the amount of consumption and supply, it indicates that North China is in a stage of water shortage in the next 15 years, not to mention that water pollution and waste still exist.
\end{abstract}

\section{Measure the Supply\& Demand of Water and Predictions}

\subsection{Solutions and Results}

\subsubsection{Water Demand}

We divide the amount of water consumption into agricultural water, industrial water and live water:

$\mathrm{W}(\mathrm{t})=\mathrm{W} \_1(\mathrm{t})+\mathrm{W} \_2(\mathrm{t})+\mathrm{W} \_3(\mathrm{t})$

in which:

W1 denotes the part of industrial water;

W2 denotes the part of agricultural water;

W3 denotes the part of resident living water.

- Industrial Water

Due to the lack of data (from 2007-2014), we cannot give an accurate prediction of the amount of industrial water in 15 years. So we optimize the method. According to statistic searching from the internet, we find that the average industrial water each factory needs is constant. In the face of mounting downward economic pressure, the number of factories is growing increasingly to promote economy growth. That is why the dynamic factor is the number of factories. We assume that the industrial water is linearly dependent with the number of factories.

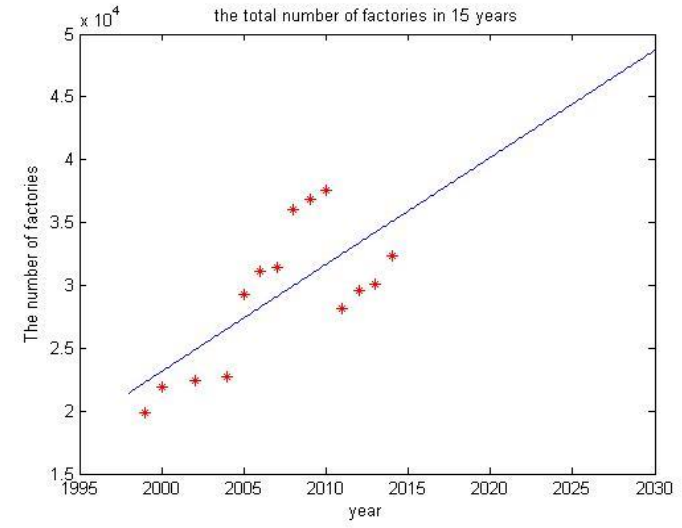

Figure 1 -a

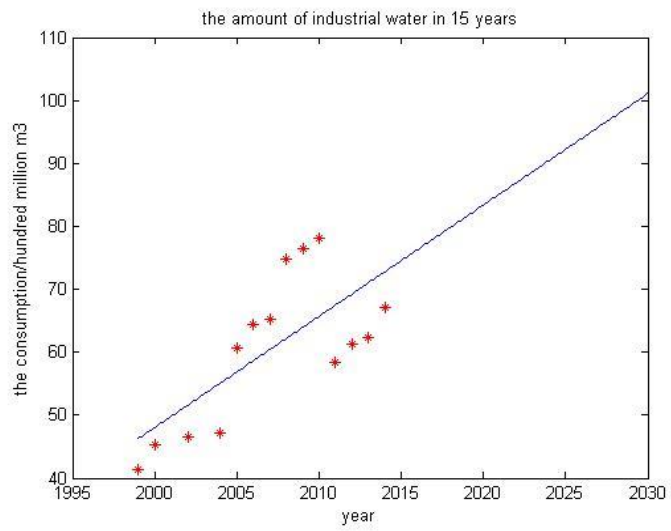

Figure $1-b$

- Agriculture Water

Water use by agriculture is primarily determined by the development of irrigated land use. In many countries and regions of the world, irrigation is the principal water user. We search the historical data from 2004-2014. And the least squares fitting method is used to predict the agricultural water consumption in 15 years. 


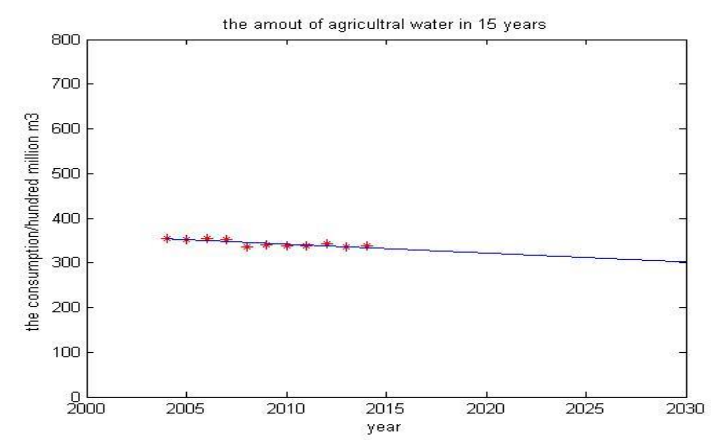

Resident Living Water

Figure 2 the amount of agricultural water in 15 years

The resident living water is linked with the population size. In this section, we consider the new policy which is encouraging childbearing. So the population quantity will increase.

Table 1 water consumption in each city

\begin{tabular}{|c|c|}
\hline City & Water consumption per capita every year/m3 \\
\hline Beijing & 97.820 \\
\hline Tianjin & 46.720 \\
\hline Hebei & 59.495 \\
\hline Shanxi & 48.180 \\
\hline Inner Mongolia & 55.115 \\
\hline Average & 61.466 \\
\hline
\end{tabular}

And referring to the water consumption per capita every year, we can get the total consumption of resident living water in $15 y$ ears.

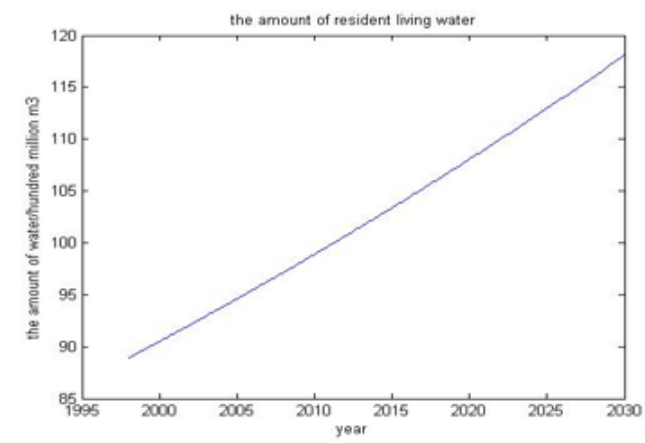

Figure 3 resident living water consumption

According to the equation, we can calculate the total amount of water consumption in 15 years.

\subsubsection{Water Supply}

The majority of human uses require fresh water. 97 percent of the water on the Earth is salt water and only three percent is fresh water. Fresh water is a renewable resource, yet the world's supply of groundwater is steadily decreasing, with depletion occurring most prominently in Asia and North America. The fresh water mainly comes from surface water, groundwater and under river flow. ${ }^{[1]}$ In this section we use historical data to predict the water supply quantity in 15 years.

Autoregressive Model Time series analysis comprises methods for analyzing time series data in order to extract meaningful statistics and other characteristics of the data. Here we use autoregressive model to predict:

y_t $=$ c_1 y_(t-1)+c_2 y_(t-2)+E_t

in which,

$\mathrm{t}$ denotes the year;

$\mathrm{c} 1$ and $\mathrm{c} 2$ are undetermined parameters; 
$\varepsilon_{\mathrm{t}}$ refers to a random disturbance term.

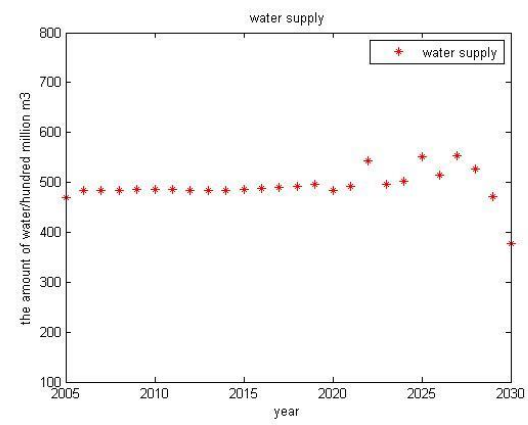

Figure 4 water supply

\section{Conclusion}

In order to compare the supply and demand of water resources in a more intuitive way, we put two curves into one paragraph: water demand curve and water supply curve.

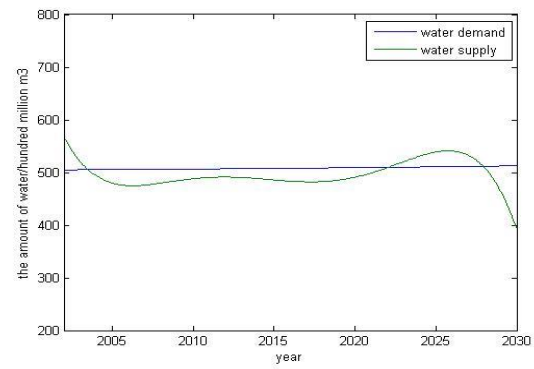

Figure 5 contrast diagram

North China is in the state of water shortage.

The water supply curve fluctuates up and down in a small range, which indicates that fresh water resources can be provided stably in 15 years. Compared with the water consumption curve, North China is, and will always be, in the state of water shortage. Especially in 2030, water scarcity is more serious. After calculating some detailed data, we get the water situation in 2030:

Table 2 water demand and supply situation

\begin{tabular}{|c|c|c|c|c|c|c|}
\hline year & living & agricultural & industrial & $\begin{array}{c}\text { water } \\
\text { amount }\end{array}$ & water supply & water deficit \\
\hline 203 & $118.0772 \times$ & $292.3350 \times$ & $102.2873 \times$ & $512.6995 \times$ & $391.6602 \times$ & $121.0393 \times$ \\
0 & $10^{8} \mathrm{~m} 3$ & $10^{8} \mathrm{~m} 3$ & $10^{8} \mathrm{~m} 3$ & $10^{8} \mathrm{~m} 3$ & $10^{8} \mathrm{~m} 3$ & $10^{8} \mathrm{~m} 3$ \\
\hline
\end{tabular}

Why will the water consumption rise smoothly?

It can be seen from the graph that the total amount of water consumption don't have significant changes. However, referring to the predictions before, we can see that the amount of industrial water is greatly increasing due to the increasing number of factories. Besides, resident living water consumption also grows significantly because of the growing population. While the agricultural water consumption decreases year by year because of the acceleration of urbanization and the decrease of cultivated land area. China is a big agricultural country, which has about 1.33 million square kilometers farmland. The region considered in this paper is North China Plain and its cultivated land area is large. So the agriculture water consumption accounts for a large proportion, which can be seen from the historical data as well. Therefore, the part of agricultural water will affect the total consumption greatly. Finally, it concludes that the total water consumption increases slowly.

Water contamination is not considered.

There is a fatal error that environment pollution is not considered in this model. Pollution of the environment in other spheres can influence the ability to provide adequate quantities of high quality drinking water or the costs and energy required to do so. Changing climate is also expected to influence water resource availability, putting more pressure on already stretched resources and 
increasing the risk of contamination due, in part, to more frequent and intense flooding. ${ }^{[2]}$ Once the water is polluted, there must be a large sum of water cannot be provided on irrigation and living.

The number of factory will decrease due to the environmental policy

Under the request of energy conservation and emissions reduction, some factories which do not conform to the standard will be forced to shut down. Meanwhile, along with the progress of science and technology, the efficiency will improve in the long run. So the quantity will not increase so fast.

\section{Reasons of water scarcity in North China}

The growing population

The North China Plains are also seeing growing tensions over water. As the population of Beijing has soared over the past several decades, the city has taken control of almost all of the major rivers flowing through surrounding Hebei Province. ${ }^{[3]}$

The amount of agricultural water is large.

As China has grown its policy of food self-sufficiency has led to extensive agricultural production in the North China Plain, a region with relatively limited natural endowment of water. The North China Plain produces around half of all of China's wheat. ${ }^{[3]}$

The climate

Although the soil of the North China Plain is fertile, the weather is unpredictable, being at the intersection of humid winds from the Pacific and dry winds from the interior of the Asian continent. This makes the plain prone to both floods and drought.

The groundwater pollution

Over pumping and contamination of groundwater is forcing cities and business to dig deeper to find clean, adequate supplies. There is a table of comprehensive assessment achievement according to the groundwater contamination assessment ${ }^{[4]}$

\section{References}

[1] Water resources from Wikipedia https://en.wikipedia.org/wiki/Water_resources.

[2] The United Nations World Water Development Report 2015.

[3] Gleick P H. China and water[J]. The world's water 2008-2009: The biennial report on freshwater resources, 2009: 79-100.

[4] Zhang Zhao-ji,Fei Yu-hong,Guo Chun-yan,Qian Yong,Li Ya-song. The Institute of Hydrogeology and Environmental Geology,Shijiazhuang 050061,China.

[5] Shiklomanov I A. Appraisal and assessment of world water resources[J]. Water international, 2000, 25(1): 11-32. 